\title{
Accountability for Community Benefit: A Reasonable Expectation for Canadian Hospitals
}

\section{Lobligation redditionnelle au service de la communauté : attentes raisonnables envers les hôpitaux canadiens}

\author{
ज्ञ \\ J. ROSS GRAHAM, CHE \\ Royal Jubilee Hospital, Vancouver Island Health Authority, Victoria, BC \\ Centre for Health Services and Policy Research, University of British Columbia \\ Vancouver, BC
}

\begin{abstract}
North American hospitals have historically struggled to engage in prevention and health promotion activities because they have not been incentivized or held accountable for doing so. However, in order to be exempt from federal taxes, 3,000 non-profit hospitals in the US must now regularly assess the health status of the communities they serve, and take action to address identified health needs. This is called "accountability for community benefit," and it is required under the Patient Protection and Affordable Care Act (commonly known as Obamacare). A modified version of accountability for community benefit warrants exploration in the Canadian context, as it may support Canadian hospitals to direct resources towards prevention and health promotion activities - something many Canadian hospitals want to do, but struggle with in the current accountability environment. This is an important health policy topic because even a small shift in focus by hospitals towards prevention and health promotion has the potential to improve population health and reduce healthcare demand.
\end{abstract}

\section{Résumé}

Les hôpitaux nord-américains doivent habituellement lutter pour pouvoir mettre en place des activités de prévention et de promotion de la santé, car ils n'y sont pas incités ou n'en sont pas tenus responsables. Cependant, afin de pouvoir bénéficier d'une exemption d'impôt fédéral, 
3000 hôpitaux à but non lucratif aux États-Unis doivent désormais évaluer, sur une base régulière, l'état de santé des communautés qu'ils desservent et prendre des mesures pour répondre aux besoins en matière de santé qui ont été repérés. Il s'agit de l'« obligation redditionnelle au service de la communauté » exigée en vertu de la loi sur la protection des patients et des soins abordables (surnommée Obamacare). Une version modifiée du principe d'obligation redditionnelle au service de la communauté vise le contexte canadien et pourrait aider les hôpitaux canadiens à affecter leurs ressources à des activités de prévention et de promotion de la santé - ce que plusieurs souhaiteraient faire, sans toutefois y arriver facilement en raison du contexte redditionnel actuel. C'est là un important sujet de politique de santé, puisqúun petit changement dans les efforts déployés par les hôpitaux pour la promotion de la santé peut donner lieu à une amélioration appréciable de la santé de la population et à une réduction de la demande de soins.

What good does it do to treat people's illnesses, to then send them back to the conditions that made them sick? (Bégin 2010:5).

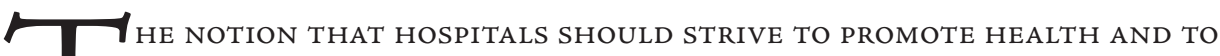 prevent (not just treat) illness and injury was popularized in Canada 30 years ago \\ L (WHO 1986). However, while many Canadian hospital leaders agreed with the} idea (and still do), progress towards this goal has been limited because few hospitals have been supported, incentivized or held accountable for engaging in prevention and health promotion activities (Graham et al. 2014; Huynh 2014). Instead, health systems across Canada typically only hold hospitals accountable for financial and clinical performance, which is important, but limited, as these areas "have only tenuous or very indirect linkage" with population health improvement (Denis 2014: 8). Similarly, the Canadian Institute for Health Information's health system performance framework does not report indicators in its "improve health status of Canadians" category by hospital (Veillard et al. 2015: 37). This scenario perpetuates the belief that prevention and health promotion are the sole responsibility of public health and primary care (Hancock 2011). Even when public health and hospitals are "integrated" within regional health authorities (RHAs), the result is often that the responsibility for population health improvement remains with public health (Moloughney 2016). Similarly, others have found that public health and hospitals can be siloed within RHAs, limiting the degree to which hospital resources can be leveraged to influence upstream determinants of health (Cohen et al. 2014; Huynh and Cohen 2012).

This is an important health policy issue because hospitals are well-positioned to improve population health using primary prevention, secondary prevention and health promotion strategies (Pelikan et al. 2013). Hospitals represent the main concentration of health system resources, skills and technology. Hospitals also have significant social capital, meaning they often represent "health" to their community (presenting opportunities for advocacy and partnerships). Hospital staff are respected and seen as credible sources of advice on health issues beyond medical treatment. 
Hospitals are also large employers (presenting opportunities for workplace health promotion), and hospital visits often occur at key moments in our lives (presenting opportunities for behaviour change). This means even a small shift in focus by hospitals towards prevention and health promotion could, in time, improve population health (Johnson and Baum 2001).

Acknowledging the important role for hospitals in population health improvement, US hospitals have faced "growing pressures to move beyond caring for individual patients to taking broader responsibility for the health of the populations they serve" (Rubin et al. 2015: 554). Part of this pressure is from a new requirement in the Patient Protection and Affordable Care Act (ACA) that 3,000 non-profit hospitals must (1) conduct regular community health needs assessments (CHNAs) and (2) demonstrate community benefit (CB) by taking action to address identified health needs, to be exempt from federal taxes. Although this approach has been controversial, its current iteration has "far-reaching implications for population health improvement, health system transformation, and health equity" (Somerville et al. 2013: 2). This article provides a brief history and description of the ACA's CHNA and CB requirements, followed by a discussion of their transferability to the Canadian context.

\section{Background}

A major distinction between private hospitals and non-profit hospitals in the US is that the later are considered charities and are expected to provide free or low-cost medical care for marginalized individuals. This "charity care" is clearly beneficial for a large number of uninsured Americans and in exchange, non-profit hospitals have long been exempt from nearly all federal, state and municipal taxes (Rubin et al. 2015). However, expansion of public health insurance in the US has made the tax-exemption of non-profit hospitals controversial. As more Americans have health insurance, there are fewer instances where hospital services are uncompensated (Burke et al. 2014). Private hospital leaders and health policy makers have also suggested that modern non-profit hospitals in the US, with highly paid executives, sophisticated operations and aggressive collection practices, barely resemble the charities that once warranted tax-exemption (Rubin et al. 2015).

In response to this criticism, the definition of $\mathrm{CB}$ and eligibility for tax exemption has changed over time (see below). In 2010, the ACA introduced the requirement that non-profit hospitals could remain tax-exempt, but would have to provide $\mathrm{CB}$ activities based on the results of regular CHNAs (Singh et al. 2015). Where the initial accountability for CB aimed to improve access to care, the ACA reform signalled "recognition among health policy makers that the prevailing medical model of focusing on treatment and cure at the expense of prevention and health promotion is ineffective and unsustainable" (Rubin et al. 2015: 554).

\section{Community benefit}

The definition of CB has changed over time (Table 1). Since 1969, CB was defined and reported at the state level, with most states using the Internal Revenue Service (IRS) definition (Rubin et al. 2015). This definition aimed to improve access, with the addition of maintaining a "community-controlled board" as a strategy to ensure unique community health needs were addressed. 
However, this definition was found to be limited and ineffective (Rubin et al. 2015). In response, the IRS broadened its definition in 2007 to include "community health improvement" activities, research, education of health professionals and contributions to community groups that engage in CB activities (Young et al. 2013). See Table 1 for a description of these items.

TABLE 1. IRS definitions of hospital community benefit

\begin{tabular}{|c|c|}
\hline 1969 Definition (Rubin et al. 2015: 547) & 2007 Definition (Young et al. 2013: I52I) \\
\hline $\begin{array}{l}\text { 1. Operate a 24-hour emergency room } \\
\text { 2. Provide charity care to the extent of the hospital's } \\
\text { financial ability } \\
\text { 3. Extend medical staff privileges to all qualified } \\
\text { physicians in the area, consistent with the size } \\
\text { and nature of the facility } \\
\text { 4. Accept payment from Medicare and Medicaid } \\
\text { programs on a non-discriminatory basis } \\
\text { 5. Maintain a community-controlled board } \\
\text { (i.e., a governing board with membership, by } \\
\text { appointment, primarily from the local community) }\end{array}$ & $\begin{array}{l}\text { 1. Charity care (i.e., subsidized care for persons who meet the criteria for } \\
\text { charity care established by the hospital) } \\
\text { 2. Unreimbursed costs for means-tested government programs (e.g., Medicare } \\
\text { and Medicaid) } \\
\text { 3. Subsidized health services (i.e., clinical services provided at a financial loss) } \\
\text { 4. Community health improvement services and community-benefit operations } \\
\text { (i.e., activities carried out or supported for the express purpose of improving } \\
\text { community health, such as conducting or otherwise supporting childhood } \\
\text { immunization efforts) } \\
\text { 5. Research } \\
\text { 6. Health professions education } \\
\text { 7. Financial and in-kind contributions to community groups (i.e., contributions } \\
\text { to carry out any of the activities that are classified as community benefits) }\end{array}$ \\
\hline
\end{tabular}

Despite its expansion, an examination of hospitals' initial reporting using the 2007 definition found that (1) access to care represented $>86 \%$ of hospital CB activities, and (2) hospitals engaged in limited community health improvement activities (Young et al. 2013). Other research demonstrated wide variation in CB spending across states, ranging from $\$ 30$ to $\$ 335$ per capita (Bakken and Kindig 2015). Because the expanded definition also did not produce the desired result, the ACA added the requirement that non-profit hospitals must conduct regular CHNAs as a condition of their federal tax-exempt status (Singh et al. 2015).

\section{Community Health Needs Assessment}

Non-profit hospitals in the US must now conduct CHNAs at least every three years to remain exempt from federal taxes. Each assessment must include consultations with community stakeholders and public health officials, and multi-hospital networks must conduct an assessment for each facility (Singh et al. 2015). Following the assessment, each hospital must develop and publish an action plan regarding how identified needs will be addressed according to the CB categories in the 2007 definition (Somerville et al. 2013). Although it is too early to tell, many report the CHNA requirement as a positive reform that will support hospitals to better contribute to population health improvement (Burke et al. 2014; Singh et al. 2015). In fact, Casalino et al. (2015: 819) report everyone in healthcare in the US is now "working to improve population health these days. Or will be very soon. Or feel that they ought to be."

\section{Accountability Leads to Action}

As reported in a special issue of this journal, Ontario hospitals are currently held accountable for financial performance, service volumes, quality and patient safety (Kromm et al. 2014). These accountabilities appear to be similar for hospitals across Canada, including those within RHAs 
(Marchildon 2013). While important, these accountabilities will have little effect on the upstream determinants of health (Alley et al. 2016; Denis 2014). Given the pressing need to prevent and manage chronic diseases, as well as reduce healthcare demand in Canada, numerous authors have proposed strategies for how Canadian hospitals can better address community health needs (e.g., Cohen et al. 2014; Neudorf 2012). These include increased public health service delivery (for hospitals within RHAs), use of a "population health lens" in decision-making, and increased collaboration with non-health sector stakeholders to address upstream health determinants. These approaches are valuable, but they rely on hospitals voluntarily directing scarce resources towards activities for which they are not held accountable and receive no compensation. Although Canadian hospitals have long seen health promotion as part of their role, hospital funding has lagged behind treatment costs and demand. This makes it challenging for hospitals to dedicate resources towards prevention and health promotion activities (Graham et al. 2014). In contrast, evidence indicates that external accountabilities drive internal accountabilities and activities within Canadian hospitals (Kraetschmer et al. 2014). In other words, accountability leads to action (Deber 2014).

I suggest the CHNA requirement and accountability for CB warrant exploration in the Canadian context. Not only is hospital accountability for CB a highly studied policy intervention, it has been refined over the past half-decade in the US. In its current iteration, accountability for $\mathrm{CB}$ has also generated considerable new research and guidance that would be valuable for Canadian hospitals (e.g., Burke et al. 2014). There are even new online "hubs" where hospitals can exchange learnings and best practices (e.g., http://www.communitybenefitconnect.org and http://www.cdc.gov/chinav/index.html).

\section{Modifications and Challenges}

With five modifications, CHNA and CB requirements could be valuable in the Canadian context. First, since all Canadians have some healthcare insurance, the definition of $\mathrm{CB}$ should be revised to focus on specific, evidence-based prevention and health promotion activities that have the highest probability of improving community health (Rubin et al. 2015). Second, the role of population health in CB should be clarified, since CB is rarely discussed in the Canadian context. This includes clarifying that "population" refers to hospitals' responsibility for improving the health of those within their geographic population, not just their client populations (see Casalino et al. 2015 for a fulsome description of the distinction between these terms). Third, since nearly all Canadian hospitals are non-profit, $\mathrm{CHNA}$ and $\mathrm{CB}$ requirements should be included in existing accountability frameworks rather than being requirements for tax-exemption. Fourth, transparency should be central to this work to support accountability and knowledge-exchange (which would be critical given the novelty of these requirements) (Rubin et al. 2015). Fifth, as most Canadian hospitals are part of RHAs, it should be made explicit that (1) CHNA and CB requirements are for hospitals - not RHAs, and that (2) these requirements are an opportunity to foster collaboration between hospital leaders and public health leaders. These are important clarifications because if RHAs are held accountable, but not hospitals, experience tells us that hospitals will resume their focus on illness care, and the responsibility for CHNAs and CB will likely fall to public health (Moloughney 2016). That said, hospitals held accountable for $\mathrm{CB}$ would be wise to collaborate with their local public health colleagues. Public health 
epidemiologists have expertise in population health assessment and likely already conduct CHNAs that could inform hospital planning. Similarly, public health staff can assist their hospital colleagues determine where health promotion and prevention strategies could be both effective and practical.

The ultimate goal is to have CHNA results inform hospital planning and resource decisionmaking. Holding hospitals accountable for CB solidifies the importance of CHNAs in hospital planning, and provides justification for hospitals to allocate resources towards activities that prevent (not just treat) illness and injury, and reduce health inequities - something that is desired, but challenging for many Canadian hospital leaders in the current accountability environment. While some Canadian hospitals would embrace these requirements (and some already have), clearly others would find them challenging given the resource constraints. Some hospital leaders might even echo the attitude expressed when the notion of "health-promoting hospitals" was first introduced: "let somebody else do it; we already have too much to do" (Lalonde 1989: 40). Hospitals should utilize existing CHNA results and collaborate with other hospitals that serve the same geographic populations. However, where no CHNA has been conducted, hospital leaders should collaborate with their public health colleagues to undertake this work. Learning from the experience of 3,000 non-profit hospitals in the US, as well as related initiatives, such as the over 1,000 member hospitals of the International Health-Promoting Hospitals Network (Pelikan et al. 2013) would also be critical. Furthermore, early and active collaboration with researchers would be wise to ensure the CHNA and resultant activities produce desired outcomes.

\section{Conclusion}

Nearly 3,000 hospitals in the US are now required to conduct CHNAs and are held accountable for demonstrating CB by taking action to address identified local health needs. This is an exciting step towards improving the impact that hospitals can have on community health - an idea originated in Canada 30 years ago. Canadian health policy makers would be wise to examine and test a modified version of this approach. While there would be initial challenges for some hospitals, the health of the Canadian population and the sustainability of our health system demand we take bold action and utilize best practices from other jurisdictions.

\section{Acknowledgements}

Thank you to Dr. Melanie Rusch for providing valuable insight regarding population health assessment in a regional health authority context.

Correspondence may be directed to: J. Ross Graham, MSc, CHE, Leader, Physician Quality Improvement; office: Memorial Pavilion KW 335, Royal Jubilee Hospital, Victoria, BC; tel:250-370-8462, ext.18462; e-mail:Ross.Graham@viha.ca.

\section{References}

Alley, D.E., C.N. Asomugha, P.H. Conway, D.M. Sanghavi. 2016. "Accountable Health CommunitiesAddressing Social Needs through Medicare and Medicaid." New England Journal of Medicine 374(1): 8-11. Bakken, E. and D. Kindig. 2015. "Does Nonprofit Hospital Community Benefit Vary by State?" Journal of Public Health Management and Practice 21(1): 18-22. 
Bégin, M. 2010. “Foreward." In J. Mikkonen and D. Raphael, eds. Social Determinants of Health: The Canadian Facts. Toronto, ON: York University School of Health Policy and Management.

Burke, J.G., S. Truong, S. Albert, J. Steenrod, C. Gibert, B. Folb, A. Saleh and E. James. 2014. “What can be Learned from the Types of Community Benefit Programs that Hospitals already have in Place?" Journal of Health Care for the Poor and Underserved 25(1): 165-93.

Casalino, L.P., N. Erb, M.S. Joshi and S.M. Shortell. 2015. "Accountable Care Organizations and Population Health Organizations." Journal of Health Politics, Policy and Law 40(4): 819-35.

Cohen, D., T. Huynh, A. Sebold, J. Harvey, C. Neudorf and A. Brown. 2014. “The Population Health Approach: A Qualitative Study of Conceptual and Operational Definitions for Leaders in Canadian Healthcare." SAGE Open Medicine 2. doi:10.1177/2050312114522618.

Deber, R.B. 2014. “What have we Learned from the Substudies?” Healthcare Policy 10(SP): 163.

Denis, J.L. 2014. "Accountability in Healthcare Organizations and Systems." Healthcare Policy 10(SP): 8-11.

Graham, R., J.A. Boyko and S.L. Sibbald. 2014. "Health Promoting Hospitals in Canada: A Proud Past, an Uncertain Future." Clinical Health Promotion 4(2): 70-75.

Hancock, T. 2011. "Health Promotion in Canada: 25 Years of Unfulfilled Promise." Health Promotion International 26(Suppl 2): ii263-67.

Huynh, T.M. 2014. "Population Health and Health Care: Exploring a Population Health Approach in Health System Planning and Decision-Making." Canadian Institute for Health Information: Ottawa, ON.

Huynh, T.M. and D. Cohen. 2012. "Innovators and Early Adopters of Population Health in Healthcare: Real and Present Opportunities for Healthcare - Public Health Collaboration." Healthcare Papers 13(3): 53-57.

Johnson, A. and F. Baum. 2001. "Health Promoting Hospitals: A Typology of Different Organizational Approaches to Health Promotion." Health Promotion International 16(3): 281-87.

Kraetschmer, N., J. Jass, C. Woodman, I. Koo, S.K. Kromm and R.B. Deber. 2014. “Hospitals' Internal Accountability." Healthcare Policy 10(SP): 36-44.

Kromm, S.K., B.G. Ross, W.P. Wodchis and R.B. Deber. 2014. "Acute Care Hospitals' Accountability to Provincial Funders." Healthcare Policy 10(SP): 25-35.

Lalonde, M. 1989. "Hospitals Must Become True Health Centres." Dimensions in Health Service 66(8): 39-41. Marchildon, G.P. 2013. Canada: Health System Review: Health Systems in Transition. London, UK: European Observatory on Health Systems and Policies.

Moloughney, B. 2016. “The Impacts on the Public Health Function with Integration with Regionalized Healthcare Systems." Prepared for Toronto Public Health: Toronto, ON. Retrieved March 31, 2016. <http://www.toronto.ca/legdocs/mmis/2016/hl/bgrd/backgroundfile-88527.pdf>.

Neudorf, C. 2012. "Integrating a Population Health Approach into Healthcare Service Delivery and Decision Making." Healthcare Management Forum 25(3): 155-59.

Pelikan, J.M., C. Dietscher and H. Schmied. 2013. "Health Promotion for NCDs in and by Hospitals: A Health Promoting Hospital Perspective." In Global Handbook on Noncommunicable Diseases and Health Promotion (pp. 441-60). New York, NY: Springer.

Rubin, D.B., S.R. Singh and G.J. Young. 2015. “Tax-Exempt Hospitals and Community Benefit: New Directions in Policy and Practice." Annual Review of Public Health 36(1): 545-57.

Singh, S.R., G.J. Young, S.Y.D. Lee, P.H. Song and J.A. Alexander. 2015. "Analysis of Hospital Community Benefit Expenditures' Alignment with Community Health Needs: Evidence from a National Investigation of Tax-Exempt Hospitals." American Journal of Public Health 105(5): 914-21.

Somerville, M.H., G.D. Nelson, C.H. Mueller and C.L. Boddie-Willis. 2013. Hospital Community Benefits after the ACA: Present Posture, Future Challenges. Baltimore, MD: The Hilltop Institute: University of Maryland, Baltimore County.

Veillard, J., B. Tipper and S. Allin. 2015. "Health System Performance Reporting in Canada: Bridging Theory and Practice at Pan-Canadian Level." Canadian Public Administration 58(1): 15-38.

World Health Organization (WHO). 1986. Ottawa Charter for Health Promotion. Ottawa, ON: WHO.

Retrieved April 11, 2016. <http://www.who.int/healthpromotion/conferences/previous/ottawa/en/>.

Young, G.J., C.H. Chou, J. Alexander, S.Y.D. Lee and E. Raver. 2013. "Provision of Community Benefits by Tax-Exempt US Hospitals." New England Journal of Medicine 368(16): 1519-27. 